their survival outcomes. Limitations of the study are acknowledged and recommendations for future research proposed.

\section{G148(P) AUDIT OF LONG BONE FRACTURES AND SAFEGUARDING ASSESSMENT IN CHILDREN UNDER 3}

JH Sims, K Bentley. Safeguarding Children Team, Bradford Teaching Hospitals NHS Foundation Trust, Bradford, UK

10.1136/archdischild-2018-rcpch.144

Aims Approximately $1 / 3$ of all children will sustain a fracture before they turn 16 years old. Most are accidental but some are due to abuse, with the younger child at highest risk. We sought to assess how robustly such young children presenting to the Emergency Department (ED) in our Trust are assessed for abuse.

Methods Both authors reviewed the notes for all children aged $<3$ years attending ED with a lower limb long bone fracture during a 12 month period 2016-2017 (36 cases).

Results 34 had appropriate safeguarding information completed at Triage. In $75 \%$ of cases, the 'mandatory' Safeguarding Questions on the ED card were completed by the doctors. Only half of the assessments included a comment about development. 8 had 'high risk' injuries by radiological type- all were spiral fractures however none were under 12 months of age. The authors were concerned about 2 of these cases which either contained insufficient information or were not discussed with paediatrics when the mechanism was not absolutely clear. Only $44 \%$ of children were fully examined. In several cases, there was disparity between the opinion given in ED and that of the reviewers. The authors felt that an extra 7 patients had potential safeguarding concerns and should have been discussed with paediatrics, with a further 6 cases where there might have been safeguarding risk but information was insufficient. Interestingly, however, all eight who were seen by paediatrics were felt to be accidental or due to an underlying condition (two had genetic bone disorders and one had rickets). In several instances, the expected actions from the reviewers were not completed - see table 1 .

\begin{tabular}{lllllll}
\multicolumn{2}{c}{ Abstract } & G148(P) & Table 1 & \multicolumn{5}{l}{ Expected actions from reviewers } \\
\hline $\begin{array}{l}\text { Social } \\
\text { care } \\
\text { check }\end{array}$ & $\begin{array}{l}\text { Social Care } \\
\text { referral }\end{array}$ & $\begin{array}{l}\text { Paed } \\
\text { Liaison } \\
\text { Form }\end{array}$ & $\begin{array}{l}\text { d/w } \\
\text { Senior } \\
\text { ED }\end{array}$ & $\begin{array}{l}\text { s/b } \\
\text { Senior } \\
\text { ED }\end{array}$ & $\begin{array}{l}\text { Referred } \\
\text { Paediatrics }\end{array}$ \\
\hline Completed & 5 & 1 & 5 & 6 & 11 & 7 \\
Not & 12 & 1 & 14 & 3 & 7 & 7 \\
completed & & & & & & \\
\hline
\end{tabular}

Conclusion Whilst some positives were demonstrated including some excellent individual assessments, use of interpreters and triage actions, the audit establishes the need for improvements in assessment of safeguarding risk.

\section{G149(P) A REVIEW OF GENERAL PRACTITIONER ATTENDANCE AT CHILD PROTECTION CASE CONFERENCES}

KCA Ferris, R Moffett, G Mackin. Paediatric Department, Western Health and Social Care Trust, South West Acute Hospital, Enniskillen, UK

10.1136/archdischild-2018-rcpch. 145
Background Child Protection Case Conferences (CPCCs) are multi-agency meetings, bringing together the various professionals involved when a concern about safeguarding has been raised.

GPs can provide key information about children and their families who are registered with the practice. They hold positive information about children and their parents as well as concerns, which can contribute to decision making around whether a child protection plan is needed. General Practitioners are invited to all CPCCs of their patients. Their attendance is infrequent.

Aims

- To understand the restrictions that prevents GPs from attending CPCCs.

- Identify ways to make it easier for GP's to attend in the future.

Methods

- List of all GP's in the local area obtained

- Questionnaire posted to these GP's

- Responses evaluated on an audit proforma

Results 201 questionnaires were posted in April 2017, 62\% responded by June. 5\% of GP's had attended a case conference within the last year, and where they had attended $60 \%$ found them to be useful and felt they had made a worthwhile contribution. Common reasons for non-attendance where lack of locum cover, time constraints and work load.

Conclusions GPs stated they would like to attend these meetings however due to time constraints, current workload and lack of locum cover this is currently impossible. They felt that video link facilities could be an alternative option. Another suggestion was the development of a standard proforma for the GP to complete. This will lead on to further work amongst the paediatric team within the trust to enable more GP's to attend CPCCs in the future.

\section{G150(P) WHAT ARE WE SAYING AND WHAT IS UNDERSTOOD?: THE LANGUAGE \& READABILITY OF CHILD PROTECTION MEDICAL REPORTS}

${ }^{1} \mathrm{M}$ Cutland, ${ }^{2} \mathrm{~J}$ Sims, ${ }^{3} \mathrm{M}$ Pye, ${ }^{4} \mathrm{C}$ Rourke, ${ }^{3} \mathrm{~K}$ McMullan, ${ }^{5} \mathrm{~A}$ Linden, ${ }^{3} \mathrm{~S}$ Jones. ${ }^{1}$ Paediatrics, Hull and East Yorkshire Hospitals NHS Trust, Hull, UK; ${ }^{2}$ Paediatrics, Bradford Teaching Hospitals NHS Foundation Trust, Bradford, UK; ${ }^{3}$ Paediatrics, Mid Yorkshire Hospitals NHS Trust, Wakefield, UK; ${ }^{4}$ Paediatrics, Calderdale and Huddersfield NS Foundation Trust, Halifax, UK; ${ }^{5}$ Paediatrics, Harrogate and District NHS Foundation Trust, Harrogate, UK

\subsection{6/archdischild-2018-rcpch.146}

Background Paediatricians write Child protection medical reports when a child has a medical assessment as part of a section 47 enquiry where there are concerns of abuse or neglect. These reports are routinely shared with children's social care and often shared with other safeguarding agencies. As such it is important that the written opinion and findings of paediatricians are clear and understood by all.

Aims To review a selection of regional child protection medical reports and to analyse the readability and language used when stating opinion. The information was then used to undertake a multi-agency survey to explore how 'what was being said' was 'being understood'.

Methods 5 Regional NHS trusts identified 88 child protection medical reports written between Jan 2016 to Jan 2017. These were analysed by a named safeguarding professional in each trust. This analysis included the extraction of statements used 
in the reports to summarise opinion and the readability level using an imbedded Microsoft office programme that provides a result comparable to school age literacy level. This information was then collated and analysed between the trusts.

The extracted statements were then used to undertake a multiagency survey to explore how different professionals interpret statements

Results 35 different statements were used in the report opinions. Two statements were used commonly. These were 'consistent' as in 'this mark is consistent with' and 'likely/unlikely' A quarter of disseminated reports had spelling errors and $27 \%$ were felt to have no clear opinion

Only $17 \%$ had a readability level likely to be readable to most adults of all literacy abilities

29 professionals completed the survey, primarily from safeguarding social work or paediatric background.

The statement with the best concordance between practitioners and shortest range of responses was 'this is highly likely to be due to non-accidental injury'. For this statement the surety of the practitioner that the presentation was due to child abuse was $90 \%$ (range $75 \%$ to $99 \%$ )

There was discordance amongst practitioners in many responses and the surety range was often wide.

\section{G151(P) SUPPORTING PARENTS OF SEXUALLY EXPLOITED YOUNG PEOPLE: AN EVIDENCE REVIEW}

D McNeish, S Scott. Research, DMSS Research, North Dalton, UK

\subsection{6/archdischild-2018-rcpch. 147}

Background Positive relationships with parents are important protective factors in young people's lives.

This review gathers evidence on what is helpful in enabling parents to maintain or rebuild good relationships where a child has been sexually exploited or serious concerns exist.

Methods The research draws on evidence from the limited research around parenting and child sexual exploitation, supplementing this with evidence from family support and parenting research more broadly.

The search strategy included

- A search of websites including those of relevant government departments, voluntary organisations and think-tanks.

- A search of multiple databases, published research, research in progress and grey literature.

The parameters of the search strategy were literature with a specific focus on 'parents' and 'child sexual exploitation' and studies of parenting in adversity.

Results A substantial amount of research which can offer valuable transferable lessons was identified.

The loudest message was that practitioners need to start with a focus on the strengths of parents and avoid assumptions of deficit or blame. Fundamentally, parents want service providers to work with them as partners in supporting their child and to be seen as part of the solution

There are some key areas in which parents will have strengths but may also experience difficulties. The difficulties experienced include:

- Parents' social support networks may be compromised by the stigma associated with sexual exploitation and the lack of understanding they may encounter within their wider family/ community.

- Their capacity for coping will be influenced by their own circumstances and their past experiences, and they will have different resilience factors in their lives.

- Parents will have different experiences of attachment, both from their own childhood and as parents.

There is good evidence that supporting parents has a direct effect on outcomes for their children.

Conclusions The report highlights the importance of supporting positive relationships which benefit the child, and outlines challenges for supporting parents and mechanisms for being more inclusive.

Overall, it gives a sense of parents as a key piece of the puzzle for addressing CSE more holistically.

\section{G152(P) PUKE AND PH}

L Rowley, K Ali, J Bursell, N Waters, M Aye. Paediatrics, Milton Keynes University Hospital, Milton Keynes, UK

\subsection{6/archdischild-2018-rcpch. 148}

Background A seven month old boy with gastro-oesophageal reflux, developmental delay and an inherited genetic abnormality had repeated admissions with vomiting and static weight. He was commenced on nasogastric (NG) feeds as he was found to have an unsafe swallow during an acute viral illness. His mother continued to report poor feed tolerance despite NG and nasojejunal (NJ) feeding.

Details of the case

During an inpatient stay at a different hospital it was observed that the mother would present 'well caught' vomitus to the nursing staff. The baby was not witnessed to be vomiting. In addition, a well secured $\mathrm{NJ}$ tube was reported by the mother to have accidentally been dislodged. These safeguarding concerns were shared with the local hospital.

On a subsequent admission to the local hospital with reported vomiting the baby was commenced on dioralyte via the NG tube. The mother continued to present 'vomit' in a bowl to nursing staff despite minimal nasogastric tube aspirates being observed. One episode raised particular suspicion as to the validity of the mother's claim.

$\mathrm{pH}$ indicator strips were used to determine the $\mathrm{pH}$ of the fluid which was presented as vomit. This was noted to be 7.5 (similar to tap water). An aspirate obtained from the baby's NG tube was 4.5 , which was similar to the $\mathrm{pH}$ of dioralyte.

The observed disparity led to initiation of child protection procedures on the basis that there was objective evidence of fabrication of illness.

Following separation from his mother the baby went on to tolerate milk feeds and solids with no vomiting. His faltering weight resolved.

Conclusion The use of $\mathrm{pH}$ indicator strips in this case confirmed the variance in $\mathrm{pH}$ between the gastric aspirate and the fluid presented by the mother as vomit. We propose the use of this simple bedside test in perplexing presentations with reported vomiting. One must remain cautious of the effect of anti-reflux medications on the $\mathrm{pH}$ of gastric fluid. It is imperative that the team consider chain of evidence and correct storage of specimens for use at a later date. 